\title{
Nickel-Catalyzed Synthesis of $\gamma$-Fluorinated Homoallylic Alcohols
}

Metal-Catalyzed Asymmetric

Synthesis and

Stereoselective

Reactions

\section{Key words}

allylation

nickel

homoallylic alcohols

Selected examples:<smiles>C/C=C(/F)[C@H](O)[C@H](CCc1ccccc1)c1ccccc1</smiles>

$X=I, 60 \%$ yield, $d r=8: 1$<smiles>C/C=C(\F)[C@H](O)[C@H](CCc1ccccc1)c1ccc(C(C)=O)cc1</smiles>

$\mathrm{X}=\mathrm{Br}, 54 \%$ yield, $\mathrm{dr}=3.5: 1$<smiles>[10B]C(C(F)=CC)[C@@H](O)Br</smiles>

16 examples

up to $75 \%$ yield

$\mathrm{ZnEt}_{2}$ (4.5 equiv)

HF-hexane $=3: 1$, r.t., $15 \mathrm{~h}$

Proposed mechanism:<smiles>C/C=C(/F)[C@H](CCc1ccccc1)[C@H](O)c1ccc2ccccc2c1</smiles>

$\mathrm{X}=\mathrm{Br}, 66 \%$ yield, $\mathrm{dr}=11: 1$<smiles>C/C=C(/F)[C@H](O)[C@H](O)c1ccccc1</smiles>

$\mathrm{X}=\mathrm{Br}, 56 \%$ yield, $\mathrm{dr}=8: 1$

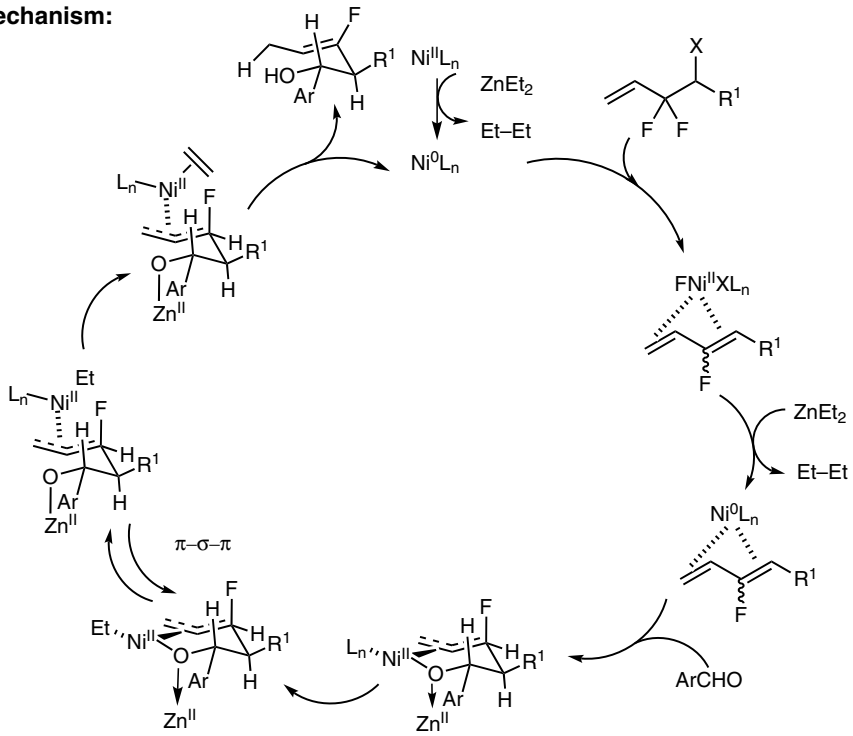

Significance: Functionalized fluoro olefins have been synthetic targets due to the ability of fluorine to alter the biological activity of organic compounds. In response to the high demand of fluorinated olefins, the authors developed a nickel-catalyzed reductive coupling of fluorinated dienes and carbonyl compounds to synthesize fluoro olefinic alcohols.
Comment: Both electron-rich and electron-deficient aromatic aldehydes undergo allylation, albeit with lower regioselectivity for electron-deficient aldehydes. The authors rationalize the Z/E-selectivity by the coordination ability of the aldehyde to $\mathrm{ZnCl}_{2}$ : for electron-rich aldehydes, the coupling reaction proceeds faster than diene isomerization, and the $Z / E$-ratio remains unchanged in the product.

SYNFACTS Contributors: Hisashi Yamamoto, Kimberly Griffin

Dol: 10.1055/s-0032-1317776; Reg-No.: H15612SF 